\title{
Para (re) pensar a América Latina: a vertente descolonial de Walter D. Mignolo
}

João Victor Sanches da Matta Machado

\section{(2) OpenEdition}

1 Journals

Edição electrónica

URL: http://journals.openedition.org/espacoeconomia/899

DOI: 10.4000/espacoeconomia.899

ISSN: 2317-7837

Editora

Núcleo de Pesquisa Espaço \& Economia

Refêrencia eletrónica

João Victor Sanches da Matta Machado, «Para (re) pensar a América Latina: a vertente descolonial de Walter D. Mignolo », Espaço e Economia [Online], 5 | 2014, posto online no dia 05 dezembro 2014, consultado o 10 dezembro 2020. URL : http://journals.openedition.org/espacoeconomia/899; DOI : https://doi.org/10.4000/espacoeconomia.899

Este documento foi criado de forma automática no dia 10 dezembro 2020.

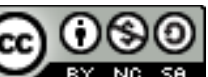

Espaço e Economia - Revista brasileira de geografia econômica est mise à disposition selon les termes de la licence Creative Commons Attribution - Pas d'Utilisation Commerciale - Partage dans les Mêmes Conditions 4.0 International. 


\title{
Para (re) pensar a América Latina: a vertente descolonial de Walter $\mathrm{D}$. Mignolo
}

\author{
João Victor Sanches da Matta Machado
}

\section{REFERÊNCIA}

MIGNOLO, Walter D. La Idea de América Latina. La herida colonial y la opción decolonial, de Walter D. Mignolo. Barcelona: Gedisa (2007 [2005]).Tradução do original em inglês: Silvia Jawerbaum e Julieta Barba. 241p.

1 Debruçar-se sobre o conceito de América Latina requer ampla percepção histórica acerca da constituição das idéias no continente americano. Em La Idea de América Latina. La herida colonial y la opción decolonial, o argentino Walter Mignolo, um dos mais destacados intelectuais pós-coloniais, adota uma postura crítica em relação a esse tema: do surgimento da palavra América até o seu desenvolvimento em América Latina, estão em jogo tanto os interesses dos impérios coloniais a fim de preservar e ampliar seus domínios territoriais quanto o das elites locais criollas, que ensejavam marcar diferença em relação aos índios e aos afro-americanos apropriando-se do pensamento europeu.

2 Fruto da expansão comercial européia e da missão cristã do século XV, a conquista do chamado - a partir de então - Novo Mundo abre uma etapa de imposições culturais sem precedentes: os colonizados foram forçados a absorver os valores europeus e assimilar sua língua, ao passo que os colonizadores pouco ou nada consideraram da cosmovisão dos habitantes locais. A matriz colonial de poder negou brutalmente a percepção dos dominados. Invenção européia, a idéia de América trazia consigo a marca da façanha de Vespúcio e, no mesmo movimento, ignorava topônimos locais como Tawantinsuyu, Anáhuac e Abya-Yala que se referiam àquelas terras. Os mapas europeus e a Igreja Católica foram dois dos instrumentos que consolidaram tal matriz. Inútil esclarecer: os "nativos" não tinham qualquer motivo para se reconhecerem da forma 
como os cristãos europeus determinaram. Todavia, de uma hora para outra, eles se tornaram bárbaros, pagãos, incultos: eis o que nos "informa" o paradigma da descoberta da América, narrativa a louvar uma Europa triunfal e vitoriosa. A esta grade analítica Mignolo opõe a invenção da América, cujas finalidades são, entre outras, interrogar a epistemologia e a política presentes no pensamento ocidental e, no momento seguinte, explorar as inúmeras versões históricas de corpos e de lugares subalternizados pela colonialidade.

3 Recusando a perspectiva histórica linear que enfatiza o caminho para o progresso e assegura a posição de liderança para a Europa, Mignolo não observa a modernidade como um fenômeno apartado do colonialismo, muito pelo contrário. Para ele o sistemamundo moderno capitalista não pode ser entendido sem a América. Investindo na heterogeneidade histórico-estrutural (MIGNOLO, 2007:72-73 [2005]), não se trata, decerto, de negar a relevância da história como ferramenta de compreensão da vida social, mas de recontá-la à luz das experiências, vozes, idiomas e culturas dos colonizados. Estamos falando de geopolítica do conhecimento, conceito elaborado pelo autor em sua já clássica obra Histórias locais/Projetos globais: colonialidade, pensamento liminar e saberes subalternos (MIGNOLO, 2003 [2000]) e retomado no decorrer das páginas de La idea de América Latina. Nesse contexto, Mignolo continua a ter Frantz Fanon como interlocutor privilegiado: destacando o livro Os condenados da terra (FANON, 2005 [1961]), os povos do Novo Mundo foram aqueles sofreram a ferida colonial, consequência de um regime racista e de um discurso hegemônico que situaram a Europa como único lócus de enunciação e com autoridade suficiente para determinar regras e padrões de história, civilização e conhecimento.

Dialogando também com Aníbal Quijano, Mignolo grifa a diferença entre o colonialismo e a colonialidade, a primeira sendo a tomada empírica propriamente dita dos territórios e a segunda a colonização do imaginário e do saber. Esta distinção é importante, pois, após o processo de independência e de formação dos Estados Nacionais na América Latina, a lógica da dominação se reestrutura: substitui-se o colonialismo externo por um interno, pois as elites locais continuam a perpetuar a exclusão dos povos que não se enquadravam no entendimento europeu de civilização. Assim sendo, quando Mignolo aponta a necessidade de descolonizar o pensamento, há que se rejeitar ambos os vocábulos - "América" e "Latina" -, uma vez que seus conteúdos trazem consigo as marcas da Europa, marcas as quais os povos ditos nativos jamais se reconheceram. Ele é taxativo a esse respeito: existirá um "após-América" e um "após-América Latina" (MIGNOLO, 2007 [2005]).

Questionado em algumas resenhas sobre algumas das posições defendidas em La idea de América Latina - sobretudo no que concerne a um suposto privilégio epistêmico dos "condenados" para tratar de assuntos coloniais -, Mignolo procura desfazer esta impressão enfatizando que a perspectiva descolonial é uma opção à monocultura do saber ${ }^{1}$ que, indubitavelmente, insiste em manter-se hegemônica no horizonte intelectual (MIGNOLO, 2008). Tal monocultura representa o privilégio do "centro" da produção do saber: a Europa. Seu projeto colonizador instaura uma lógica hierárquica que localiza a si própria no patamar mais alto do desenvolvimento civilizatório e, consequentemente, a maior parte do mundo encontra-se em estágio de barbárie. Portanto, caberia à Europa a tarefa de civilizar os povos, contar suas histórias e, se possível, desenvolvê-los... Contudo, através de diversas práticas de opressão cultural, a colonialidade força o povo oprimido à marginalidade, obrigando-o a aceitar a cultura imperialista (FANON, 2005 
[1961]). Todavia, é exatamente tal imposição que engendra as condições necessárias para o surgimento do pensamento fronteiriço, movimento de contestação das relações assimétricas entre o colonizador e o colonizado que visa descentralizar a geopolítica do conhecimento e apresentar uma alternativa aos condenados.

6 A imagem de uma Europa desenvolvida está ligada à retórica da modernidade, cuja representação acabou por ocultar os efeitos da matriz colonial de poder. A partir do século XX, registra Mignolo, os Estados Unidos também passam a integrar tal imagem, o que lhes dotou força suficiente para reproduzir padrões neoliberais convenientes aos interesses político-econômicos do país e de suas empresas. No interior do sistemamundo moderno, constitui-se a reprodução do domínio econômico, político e social que o centro exerce sobre a periferia. A luta anti-sistêmica, como definida por Immanuel Wallerstein, não ocorre da mesma forma no centro e na periferia. As batalhas sociais no centro são conflitos de classe em que os trabalhadores reivindicam direitos, porém ainda com preceitos sustentados no racismo e na xenofobia que, apesar das conquistas sociais, ainda reproduzem a dominação no sistema mundo. Já os conflitos na periferia teriam em sua constituição elementos anti-imperialistas que, para além das questões econômicas e materialistas, ocorrem em meio a disputas ligadas a direitos étnicos e culturais (WALLERSTEIN, 1974).

7 São precisamente estas últimas que chamam a atenção de Mignolo, pois encarnam a possibilidade de contar a história para além das vertentes intelectuais críticas oriundas do mundo "ocidental". Ao tomar como referências o pensamento de Felipe Guaman Poma de Ayala, Aníbal Quijano e Gloria Anzaldua, além de aproximar-se do zapatismo, do Fórum Social Mundial e da Universidade Intercultural das Nacionalidades e Povos Indígenas Amawtay Wasi, ou seja, ao contribuir para a emergência de falas e de saberes indígenas, mestiços, femininos, africanos e ameríndios, a opção descolonial imediatamente põe em xeque as quatro ideologias totalitárias da modernidade cristianismo/conservadorismo, liberalismo, colonialismo e, mesmo, o marxismo, que, embora reconhecidamente emancipatório e crucial na compreensão da trajetória do capital e da exploração do trabalho, é incompatível com a lógica anti-universalista e anti-homogeneizadora proposta por Mignolo (MIGNOLO, 2007:174 [2005]) e outros autores pós-coloniais ${ }^{2}$. Nem mesmo Edward Said (SAID, 2007 [1978]) escapa de sua perspicácia: segundo Mignolo, ele não conseguiu alcançar que a constatação de um orientalismo significa a existência prévia de um ocidentalismo, cuja incidência primeira ocorre no Novo Mundo entre os séculos XV e XVIII. Assim, ainda conforme Mignolo, o orientalismo dos séculos XIX e XX seria um segundo momento do ocidentalismo (MIGNOLO, 2007:59-68 [2005]).

8 No posfácio à edição espanhola, Mignolo acompanha com otimismo a ascensão de Evo Morales à presidência da República na Bolívia e suas modificações na estrutura do Estado (idem, pp.213 e 215). Estamos diante de obra com acentuado teor histórico, e é notadamente este aspecto que faz dela farol para o devir. Após ler sua convincente argumentação, não será fácil defender a face Latina da América em nome de uma união dos povos oprimidos pelos impérios europeus e, recentemente, pelos Estados Unidos. Tanto latinidade quanto América são assaz estranhas ao projeto de esquerda descolonial confeccionado por Walter Mignolo. Como não lhe dar razão? 


\section{BIBLIOGRAFIA}

FANON, Frantz. Os condenados da terra. Juiz de Fora: Editora UFJF (2005 [1961]).

MIGNOLO, Walter D. La idea de américa latina: la herida colonial y la opción decolonial. Barcelona: Gedisa (2005).

MIGNOLO, Walter D. Novas reflexões sobre "Ideia da América Latina": a direita, a esquerda e a opção descolonial. Caderno CRH, v.21, n.53, p. 239-252 (2008).

SAID, Edward W. Orientalismo: o oriente como invenção do ocidente. São Paulo: Companhia de Bolso (2007 [1978]).

SANTOS, Boaventura de Souza. A sociologia das ausências e a sociologia das emergências: para uma ecologia dos saberes. In: SANTOS, Boaventura de Souza (org.). Renovar a teoria crítica e reinventar a emancipação social. São Paulo: Boitempo (2007).

SANTOS, Boaventura de Souza. Pela mão de Alice: o social e o político na pós-modernidade. São Paulo: Cortez (1996 [1995]).

WALLERSTEIN, Immanuel. The rise and future demise of the world capitalist system: concepts for comparative analysis. Comparative Studies in Society and History, volume 16, p.387-415 (1974).

\section{NOTAS}

1. Termo utilizado pelo português Boaventura de Sousa Santos para rechaçar o eurocentrismo e seus desdobramentos epistemológicos (SANTOS, 2007).

2. Boaventura de Souza Santos também demarca distância entre seu pensamento e o materialismo histórico-dialético: apontando determinadas fragilidades desta corrente, ela acaba sendo parte do problema mais que da solução quando da emergência da pósmodernidade (SANTOS, 1996 [1995]).

\section{AUTOR}

\section{JOÃO VICTOR SANCHES DA MATTA MACHADO}

Estudante de graduação em Relações Internacionais da Universidade Federal Rural do Rio de Janeiro, bolsista PIBIC/CNPQ. Resenha escrita no âmbito do projeto de investigação A geografia como geopolítica do conhecimento: diálogos pós-coloniais, sob orientação do professor Guilherme Ribeiro (LAPEHGE/UFRRJ). 